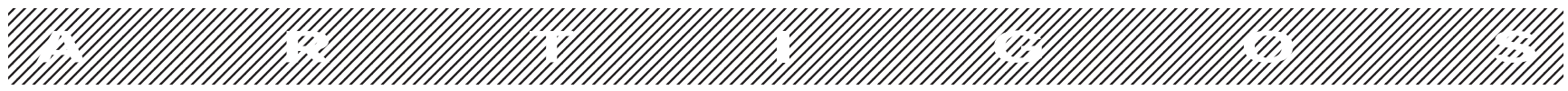

\title{
Construtivismo ou construcionismo? Contribuições deste debate para a Psicologia Social
}

\author{
Ronald João Jacques Arendt ${ }^{1}$ \\ Universidade do Estado do Rio de Janeiro
}

\begin{abstract}
Resumo
Neste artigo serão discutidas duas abordagens contemporâneas da Psicologia, o Construcionismo e o Construtivismo, a primeira proveniente da Psicologia Social, a segunda da Psicologia do Desenvolvimento. Ainda que aparentemente conflitantes - o Construcionismo procura dar conta das construções que os indivíduos elaboram coletivamente, enquanto o Construtivismo busca dar conta da construção das estruturas cognitivas que o indivíduo elabora no decorrer do seu desenvolvimento -, o argumento do trabalho busca indicar que ambas as propostas teóricas se reportam aos princípios conceituais da filosofia pós-moderna: crítica ao acesso possível a uma realidade independente do indivíduo, rejeição de um enfoque cartesiano de investigação científica fundado no rigor e na objetividade. Entretanto, as análises efetuadas permitem concluir que os modelos considerados efetuam uma redução, seja para o nível social, seja para o individual. O artigo finaliza com uma tentativa de integração de ambos, como proposta de fugir ao desequilíbrio típico das teorizações na Psicologia Social que, tradicionalmente, sempre colocou ênfase ou no indivíduo ou no contexto em seus modelos teóricos.
\end{abstract}

Palavras-chave: construtivismo, construcionismo, psicologia social, filosofia pós-moderna.

\begin{abstract}
Constructivism or constructionism? Contributions from this debate to Social Psychology. This paper will discuss two contemporary approaches of psychology, constructionism and constructivism, the first one coming from Social Psychology, the other from Developmental Psychology. Even seemingly conflicting constructionism tries to cope with constructions collectively elaborated by individuals, while constructivism tries to cope with the construction of cognitive structures elaborated by the individual during his development -, the argument seeks to indicate that both theoretical proposals are related to the conceptual basis of postmodern philosophical thought: critique of a possible access by the individual to an independent reality, rejection of a Cartesian approach of scientific inquiry grounded in the search of rigor and objectivity. However, the analysis fulfilled allows to the conclusion that the models considered accomplish a reduction, be it to the social or to the individual level. The paper finishes with a trial to integrate both models, a proposal to escape to the typical absence of balance in the psychological theorizations of social psychology, whose tradition is to emphasize the social or the individual in its theoretical models.
\end{abstract}

Key words: constructivism, constructionism, social psychology, postmodern philosophical thought.

\section{Introdução}

$\mathrm{E}$ ste trabalho é fruto das minhas investigações sobre a modernidade, o modernismo, e o pós-modernismo no pensamento contemporâneo e sua relação com a construção teórica em Psicologia. Partindo da história da Psicologia, acompanhamos o raciocínio da filósofa e psicóloga alemã Nicole Schmidt (1995) para quem a história da Psicologia é também a história de seu afastamento da Filosofia. Esta é uma história eminentemente alemã que, do final do século XIX ao início do último, num período de pouco mais de quarenta anos (1879 a 1921), lançou a Psicologia num debate caracterizado por controvérsias que até hoje permanecem praticamente sem solução. Este debate poderia ser sintetizado pelas divergências entre Wilhelm Dilthey e Hermann Ebbinghaus (aluno de Wilhelm Wundt), embora existam desdobramentos posteriores que sofistiquem a discussão. Enquanto o primeiro 
entendia não ser possível estudar o homem na forma experimental proposta pelo segundo, o segundo não podia admitir a dicotomia entre as ciências do espírito e ciências da natureza proposta pelo primeiro.

Dilthey propunha uma divisão entre os modos de acesso ao conhecimento de uma ou outra modalidade científica: para as ciências do espírito, as Geisteswissenschaften, cabia compreender os fenômenos sociais, culturais, nos quais se inseria um sujeito valorativo que experenciava fatos historicamente situados. Era o Verstehen, a compreensão, que configurava um quadro totalmente contrastante ao Erklären, a explicação, modo analítico típico das Naturwissenschaften, ciências da natureza. Dilthey questionava a disposição de Wundt e Ebbinghaus de imporem o modelo de uma máquina, que se desmonta e se torna a montar, às ciências do homem.

No mínimo surpreendente será encontrarmos, décadas depois, a mesma discussão nos debates da Psicologia pósmoderna contemporânea. John Shotter, por exemplo, influente psicólogo do movimento do construcionismo social, liderado por Kenneth Gergen, sugere que abandonemos a burocracia dos modelos teóricos da Psicologia Social experimental, pois não haveria como retirar o sujeito da rede de significações lingüísticas do contexto cultural onde está inserido. Mais surpreendente ainda é encontrarmos autores contemporâneos como Leandert Mos atribuindo a Dilthey o papel de precursor do pensamento pós-moderno em Psicologia. A surpresa não decorre tanto do conteúdo de tais análises mas da constatação de que, passados cem anos, o status da discussão continua o mesmo. Claro que muita coisa mudou: saímos do "psicologismo" do início do século XX, para cairmos no "sociologismo" dominante ao final dele. Mas a controvérsia denunciada por Nicole Schmidt permanece.

É nesse sentido meu interesse no debate filosófico do modernismo e do pós-modernismo, que teve origem na crítica à concepção de ciência que emerge nas ciências humanas a partir da segunda metade do século XX, particularmente na crítica ao dito "método cientifico" fundado na metafísica e no racionalismo cartesianos. Um aprofundamento da questão indica, porém, que o debate é bem mais complexo do que podemos imaginar. Constate-se que sua dimensão vai muito mais além de uma mera discussão metodológica nas ciências. Ele envolve problemas de ordem político-econômica, estética, sociológica, cultural, científica e tecnológica, que emergem a partir do Iluminismo.

Convém partir de uma definição dos termos a serem utilizados. Segundo Marilena Chauí (1992), embora "simplificando extremamente o que em si é de extrema complexidade, diremos que a modernidade é um projeto que se desenvolve durante o processo de desenvolvimento e queda do Antigo Regime ou das monarquias absolutas (...), enquanto o modernismo poderia ser datado a partir da revolução e reação conservadora de 1848 e, finalmente, o pós-modernismo estaria datado a partir dos anos 70 de nosso século, sob os efeitos das mudanças do modo de produção capitalista” (p. 383).

Para Scott Lash (1990) uma questão não resolvida é se o modernismo constituiria um aprofundamento ou um enfraquecimento do projeto iluminista da modernidade. O moder- nismo seria assim uma "configuração tridimensional” como ruptura e aprofundamento da racionalidade iluminista e como um novo caminho para a razão instrumental. Caberia indicar algumas associações que este autor estabelece em sua proposta de periodização histórica. Assim, a cultura realista a seu ver é afim à nascente burguesia do final do século XVIII e início do século XIX, enquanto o modernismo estético, que emerge como paradigma cultural no decorrer do século XIX será afim às estruturas do capitalismo organizado - entendase aqui a acumulação do capital, o surgimento das corporações monopolistas, da classe trabalhadora organizada, do rápido crescimento das grandes metrópoles.

Ocorrem então no modernismo e pós-modernismo duas ordens de desequilíbrio, frente ao realismo clássico: enquanto a cultura modernista procurará desestabilizar a racionalidade iluminista da identidade burguesa, o pós-modernismo pretenderá desorganizar a sociedade e economia capitalistas. Modernismo e pós-modernismo poderiam ser compreendidos como processos com formações específicas, a primeira caracterizada pela diferenciação cultural, a segunda caracterizada por sua des-diferenciação.

Neste artigo, proponho-me a desenvolver este debate no ambiente conceitual da Psicologia, particularmente da Psicologia Social. Que contribuição teórica as análises pós-modernas poderiam dar à Psicologia Social? Uma das propostas deste trabalho será argumentar a favor de um não reducionismo do psicológico ao social ou do social ao psicológico. Veremos que o construcionismo e o construtivismo, ambos movimentos teóricos passíveis de serem classificados como pósmodernos, caminham em direções opostas, um, para o “sociologismo”, outro, para o “psicologismo”.

Para melhor compreendermos as posturas reducionistas, para o lado do social ou do psicológico, podemos dar um exemplo no âmbito dos processos cognitivos. Assim, conceitos psicológicos como a consciência, a inteligência ou a mente seriam características do indivíduo ou fruto das relações que este indivíduo estabelece num contexto social? Tais características seriam biológicas, sendo, portanto, localizadas no cérebro do indivíduo. Ou o cérebro entraria como fator indispensável - ao fornecer os recursos e os limites do fazer humano -, mas apenas através da participação do indivíduo numa cultura tais características adquiririam sentido conceitual?

No contexto da história da Psicologia Social torna-se possível caracterizar uma Psicologia Social psicológica e uma Psicologia Social sociológica, incompatíveis entre si, buscando sempre trazer seu objeto para um ou outro lado da dicotomia indivíduo/sociedade, mantendo-se sempre os campos em posições antagônicas. Ao buscar colocar esta dicotomia em discussão, através da exposição dos dois modelos, do construcionismo e do construtivismo, quero propor a independência dos níveis de análise: cada nível pode existir sem que um seja reduzido ao outro. Ao mesmo tempo em que somos o produto das forças sociológicas, políticas que nos cercam, podemos criar formas diferentes, discordantes e que falam a favor de nossa singularidade de indivíduos e grupos. Dada esta independência, o desafio epistemológico 
consistirá em estabelecer as relações possíveis entre os modelos considerados. O debate que dá título ao artigo e a tentativa de solução que irá ser proposta se encaixa no contexto deste desafio.

\section{O Construcionismo}

Para caracterizar o construcionismo partirei do volume editado por Tolman, Cherry, Hezewijk e Lubek (1996) a partir da $6^{\underline{a}}$ Conferência Bienal da Sociedade Internacional de Psicologia Teórica, ocorrida no Canadá, em 1995. Em sua seção inicial, John Shotter, da Universidade de New Hampshire e Kenneth Gergen, do Swathmore College, dois nomes dos mais representativos do construcionismo, discutem questões teóricas contemporâneas da Psicologia, com comentários críticos de Leon Rappoport, da Kansas State University, e Leandert Mos, da Universidade de Alberta. Acredito ser pertinente acompanhar a argumentação dos autores e as conseqüentes avaliações críticas a que tais argumentos serão submetidos. O tema disparador das palestras era "Repensar a psicologia e a teoria” .

Ainda no resumo, Shotter ressalta sua tarefa de discutir outras formas de conhecer do que as disponíveis para nós através do projeto da epistemologia tradicional. Seu trabalho, cujo título é "Wittgenstein na prática: da teoria à poética social” apóia-se principalmente na última fase do pensamento do filósofo austríaco que, segundo Shotter, oferece para nós, cientistas modernos individualistas, autocentrados, autocontidos e "obcecados com o conhecimento e a informação” um sentido ontológico das diferentes formas de contato com o meio, em seu "fluxo contínuo, contingente de interação entre pessoas, entrelaçado pela linguagem”, campo para a expressão não de quadros ou representações, mas de relações continuamente estabelecidas pelas pessoas através da conversa, do diálogo.

A exploração das possibilidades relacionais propõe então ao pesquisador uma nova postura metodológica. Métodos devem ser viáveis e fundados em nossas práticas ordinárias do dia a dia, tornando possível a participação de pessoas comuns sem que elas precisem "aprender disciplinas especiais ou particulares ou atingir padrões ou passar provas estabelecidas por aqueles já admitidos como especialistas”. Explicações teóricas serão então "não apenas desnecessárias como também prejudiciais”, pois ao buscarmos princípios teóricos gerais escondidos atrás das aparências, “algo que irá nos explicar uma circunstância de forma intelectual e passiva”, deixamos de perceber "nossas práticas envolvidas na fala”. Reagir simplesmente ou responder de forma a tornar possível manter nossos relacionamentos, explorar nossas respostas e reações “pré-teóricas”, “pré-intelectuais” será o suficiente, na leitura de Wittgenstein efetuada por Shotter.

Enviar mensagens; compreender o outro em profundidade; discursar de forma rotineira e hábil sobre um assunto; ser capaz de “ir além”, por assim dizer, de um jogo de linguagem, falar sobre 'contatos' efetuados, formular 'teorias' sobre a natureza do que está 'lá': todas estas habilidades são, ou podem ser, desenvolvimentos posteriores (tradução do autor, p. 9).
Quais seriam então, a partir de Wittgenstein, os métodos disponíveis para nossas investigações como profissionais, pergunta Shotter? Interromper, através de formas de linguagem, imagens, metáforas, o fluxo de nossa atividade, responde ele, provocando-nos a examinar se existe mais do que havíamos esperado em determinadas circunstâncias, assim como as formas de nos relacionarmos com elas, comparando estas formas de falar com outros possíveis jogos de linguagem. Permitir ver novas conexões com o meio. Embora o profissional não possa usar seus métodos para afirmar a natureza dos processos envolvidos, ele pode utilizar sua habilidade para instruir os outros a ver a natureza no contexto de suas práticas, e sinalizar que, antes de simplesmente, de forma passiva, as pessoas verificarem que algo "seja” desta ou daquela forma, elas captem algo de novo, ainda não visto, na articulação emergente de suas falas e atividades. Nesta postura, ao se interessar pela criação deliberada de circunstâncias sociais que conduzam a uma nova compreensão das redes de conexões e relações entre eventos, o profissional estaria assumindo uma “poética social”. "O que é novo nisso tudo, é chegarmos a uma compreensão mais direta e imediata de como lidar com nossas práticas, na prática, utilizando métodos que ultrapassem toda a tentativa de primeiro compreendê-las em termos de teorias" (p. 11).

O artigo de Gergen (1996) envolve a teoria, formulando uma questão: se novos desenvolvimentos na semiótica, na teoria literária e na filosofia da linguagem indicam que teorias não podem dizer a verdade, não podem ser falseadas fora de uma cultura, comunidade ou ideologia particulares, não estaria o projeto teórico da Psicologia se aproximando de uma crise, uma ameaça beirando sua aniquilação? Deveríamos nós aceitar estas conclusões niilistas? Sua resposta será propor uma concepção de teoria que, ao invés de "efetuar predições para o futuro”, criaria “o futuro através do diálogo”. Este recurso deveria:

(1) envolver a avaliação crítica de práticas culturais (incluindo as práticas das ciências humanas); (2) permitir a geração de formas inteligíveis para a ação - bases racionais para ações ou políticas pessoais ou coletivas; (3) alterar padrões de conversa - quando formas de linguagem diferentes, metáforas, mudanças no argumento, são colocadas para troca, relações também são modificadas; (4) criar imagens para futuros alternativos (tradução do autor, p. 14).

Os problemas concretos encontrados nas práticas da política da identidade, “descendentes ocidentais de uma ideologia individualista”, tais como as posturas realistas ou essencialistas freqüentemente nelas identificadas, são o argumento através do qual Gergen irá conceituar o processo que ele chamará de política relacional, expressão prática de sua concepção de teoria. As políticas da identidade, ao substituírem o indivíduo pelo grupo, como centro de referência, não romperam com o individualismo: o grupo permanece “discursivamente tratado como indivíduo”.

Para Gergen, porém, a "sensibilidade relacional” pode ser antevista em exemplos recentes de autores como Stanley Crouch, no qual afro-americanos são tratados não como um 
grupo de estrangeiros (outsiders), mas participantes em enclaves de grande alcance, como votantes, pagadores de impostos e pensadores sérios. Ou Todd Gitlin, que fala de uma "política de comunalidade" orientada em torno da compreensão de diferenças, contra um pano de fundo daquilo que não é diferente e é compartilhado entre os grupos. O que estaria ocorrendo seria uma re-teorização do self e do outro. "Confrontamos a possibilidade de desenvolver formas inteligíveis que vão além da identificação de unidades separadas - eu contra você, nós contra eles - o que pode criar a realidade da relação, o dado palpável do que é inseparável” (p. 19).

Ratificando a posição de Vygotsky e de Bakhtin, na qual o indivíduo é concebido como inseparável do processo social, Gergen irá aplaudir o "deslocamento da psicologia do longo investimento no processo cognitivo autocontido" e sua substituição por uma concepção mais socializada do self. Nesse sentido, “o agente autônomo” seria um mito; “cada um de nós é constituído pelo outro; não podemos deliberar ou decidir sem implicar a condição do outro” (p. 19). Não será, porém, suficiente a transformação de recursos teóricos: torna-se urgente introduzir formas inovadoras de ação política. “A política no modo relacional” conclui Gergen, “deveria ser tanto sutil quanto ininterrupta - não o trabalho de grupos específicos em lugares identificados como 'políticos', mas o trabalho de todos nós, em todas as frentes” (p. 21).

Diversas publicações de Shotter $(1992,1997,1998)$ e Gergen (1973, 1980, 1992, 1994, 1996, 1998), permitem conferir a coerência das posições acima assumidas por ambos. Ambos autores são psicólogos sociais consagrados, que integram o movimento da “construção social”, e de forma explícita assumem a posição pós-moderna na Psicologia. Antes de pautar suas idéias a partir de Wittgenstein, Shotter (1992) ressalta o movimento da ciência moderna em direção à ciência pós-moderna, de um estilo, no qual um observador afastado testa suas teorias, para um modo interativo, onde um observador participante testa procedimentos de forma interessada.

Os dois paradigmas são contrastados a partir de uma dicotomia: de um lado teorias, objetos, sujeitos que executam procedimentos e refletem sobre coisas a partir de seus interesses, representando a realidade, confiando nas próprias experiências como forma de compreender o mundo, investigando baseados em fundamentos considerados legítimos; do outro, práticas, atividades, sujeitos que negociam a coordenação de ações sociais com outros no fluxo cotidiano, em função de interesses compartilhados, questionando os processos de "construção social" da realidade, atuando com modos de investigação que aceitam o erro e encontram suas garantias em situações localmente constituídas.

Shotter (1997), no contexto da crítica à "revolução cognitiva” proposta por Howard Gardner, e já imerso no universo do filósofo austríaco, oporá à "ideologia burocrática e tecnocrática" do cognitivismo a ética relacional e o "momento de interação" pensado a partir da noção de cognição como prática social. Shotter (1998) discute a existência de práticas disciplinares na Psicologia moderna, questionando as instâncias monológicas da metodologia convencional e propon- do em seu lugar uma prática poética fundada nas relações responsáveis, dialógicas da construção social.

Há mais de vinte e cinco anos Kenneth Gergen vem procurando colocar em discussão o modelo dominante da Psicologia nos Estados Unidos. Em Gergen (1973) ele já questionava o sentido da Psicologia Social enquanto Naturwissenschaft e propunha que ela fosse vista como Geistwissenschaft. A Psicologia não poderia ser a "ciência da interação humana”, pois não era possível para o psicólogo estabelecer leis gerais através da observação sistemática. Os fatos da Psicologia Social estariam historicamente circunscritos, e ela deveria se transformar em pesquisa histórica.

Em Gergen (1980), sua análise se dirige ao modelo de pesquisa adotado na Psicologia contemporânea. Três idéias subjacentes a este modelo são objeto de sua crítica: a assunção de que proposições teóricas gerais são sujeitas a avaliações empíricas (a idéia de que a probabilidade de uma proposição ser válida será função do número de confirmações observadas); a assunção correlata de que o conhecimento seria cumulativo e, finalmente, a assunção (central na tradição empírica e positivista) de que "teorias da disciplina, quando utilizadas de forma correta, podem ser usadas para o bem social geral” (p. 255), num amplo e variado conjunto de objetivos visando a previsão e o controle de fatos. Esta dicotomia levaria à distinção comum entre uma Psicologia Social “pura” oposta a uma outra, “aplicada”. O tema do artigo é indicar a necessidade de um modelo alternativo que se oriente para a investigação social, para a base social da teoria em Psicologia Social, considerando-se o quanto imprevisível seria a ação humana.

A Psicologia Social necessitaria de mais “audácia intelectual”. Esta envolveria teorias que viessem a refletir sobre as formas de interpretação do senso comum, teorias que ao colocar em discussão "assunções orientadoras da cultura” levantariam questões fundamentais da vida social, "fomentando a reconsideração do que é dado como garantido e fornecendo então novas alternativas para a ação social” (p. 261). Em seus textos mais recentes, Gergen $(1996,1998)$ irá retornar à ênfase no sujeito psicológico como "confluência de práticas discursivas", de forma a tornar viável a "reconstrução social da mente", dada a impossibilidade de um estudo da pessoa no ambiente do laboratório. As tentativas deveriam ser no sentido de "enriquecer" a Psicologia de forma a favorecer transformações positivas da sociedade.

O comentário de Rappoport (1996) é conciso e se dedica principalmente à análise do texto de Gergen. Este, ao procurar ilustrar a viabilidade de sua política relacional, atinge uma “qualidade evangélica” na sugestão de formas que venham a expandir as possibilidades de transformação coletiva. A formulação das políticas relacionais

(...) mantém sua plausibilidade e admirável apelo ideal apenas na medida em que a existência de drásticos diferenciais de poder político e econômico são ignorados. (...) O fato de grupos de interesse em competição raramente serem iguais em poder, e dificilmente estarem dispostos a voluntariamente abrir mão de qualquer uma de suas vantagens no poder, não necessita 
maior elaboração. Resta ser visto se a idéia de uma política relacional é viável numa sociedade competitiva, materialmente estruturada de tal forma a encorajar grupos de interesses disparatados a lutar por vantagens no poder por quaisquer meios que não sejam fortemente ilegais (tradução do autor, p. 36)

Nesse sentido, a crítica às políticas da identidade, efetuada por Gergen “pode parecer reacionária para aqueles preparados para argumentar que as políticas identitárias e o multiculturalismo a elas associado ainda é uma das melhores esperanças para progressos liberatórios futuros. Além disto, há também a possibilidade (paranóide como possa soar) de que, aceitando a crítica às políticas da identidade como não sendo mais úteis, se possa inadvertidamente avançar agendas de grupos de interesse reacionário” (p. 35).

O comentário de Mos (1996) é mais complexo. Trabalhando mais os acordos entre os autores do que seus desacordos, Mos utilizará o recurso de comparar "seu compromisso comum com a natureza prática da teoria” com os argumentos do filósofo alemão Wilhelm Dilthey. Este há muito já dizia que as práticas da vida estariam na origem das ciências humanas e seus esforços teóricos, mesmo nas suas manifestações mais abstratas. A teoria nas ciências humanas seria prática na medida em que a formulação de nossas explicações sempre submergiria aos interesses derivados do contexto social no qual ela fosse formulada. Nossa relação com o mundo não poderia ser teórica - ou, divina - pois somos participantes do mundo, antes de conhecê-lo. Numa tradição que reporta a Dilthey e, um século antes a Johann Gottfried Herder, o conceito de 'vida' será concebido não como uma categoria biológica, mas histórica e biográfica, tendo sua base na natureza, articulada porém ao mundo sócio-histórico. Deste ponto de vista, a Psicologia como ciência humana seria a vida compreendida da perspectiva do indivíduo e pessoas seriam "pontos de interação”, únicas, mas totalmente implicadas no mundo.

Tanto a reivindicação de Shotter, de que nossas práticas relacionais sejam estendidas para além dos nossos limites disciplinares, quanto a de Gergen de que os discursos radicais da relação sejam essencialmente 'políticos', são ecos da visão de Dilthey de que a vida individual está sempre aberta à coerência mais profunda da humanidade como um todo, e que as várias formas de coerência social e cultural são contínuas às relações vividas da existência individual (tradução do autor, p. 42).

Talvez precisássemos retornar ao século dezenove para mais uma vez encontrar um mundo de discurso que invoque a vontade humana, considera Mos, como uma resposta àquelas condições de vida mediadas por nossa maior ou menor compreensão de nós próprios e dos outros. De certa forma é o que os autores considerados procuraram realizar.

Quando Shotter escreve que ele quer explorar nossas 'subjetividades relacionadas', que ele quer 'compreender algo que já esteja facilmente às nossas vistas' e que fazer isto é estudar 'as atividades entrelaçadas da fala' que ocorrem nos 'espaços continuamente transformados entre as pessoas' ele se encontra seguindo Herder e Dilthey, naquilo que Charles Taylor intitulou de tradição 'expressivista’. (...) Taylor convincentemente mostra que esta última concepção facilitou a mudança, característica do pensamento romântico, do 'logos' à 'poesis', uma mudança da expressão da razão à das emoções. Além disto, de acordo com a concepção implícita de Herder, da linguagem como expressão antes de designação, os românticos entenderam a linguagem no modelo da significação da arte - a vida é como a arte - dando conta e clarificando seu significado na expressão (tradução do autor, p. 43).

Ao propor uma "poética social” no lugar da "teoria”, Shotter parece compreender a linguagem como veículo caracteristicamente humano de consciência, no qual participantes de uma “dança” se permitam 'ir' com os outros.

Primeira conclusão: o construcionismo tende ao sociologismo.

\section{O Construtivismo}

Classicamente o construtivismo reporta à obra de Jean Piaget, no contexto teórico dos processos cognitivos. O grande psicólogo suíço sistematizou o enfoque, compartilhado pela maioria dos construtivistas, que consiste na hipótese mestra de que não existem estruturas cognitivas inatas, sendo estas construídas pelo sujeito, no decorrer de suas ações no meio. Não é aqui o local adequado de aprofundar as posições piagetianas, já do domínio público; meu interesse, nesse artigo, é introduzir o construtivismo através do pensamento do psicólogo alemão Ernst von Glasersfeld, professor da Universidade de Massachussets.

Tomei contato pela primeira vez com suas análises num texto organizado por Dora Fried Schnitmann (1994) intitulado “Novos Paradigmas, Cultura e Subjetividade”. No debate que se segue a uma palestra de Evelyn Fox Keller (física do MIT discorrendo sobre os paradoxos da subjetividade científica), esta recebe uma crítica surpreendente de Glasersfeld (citado por Schnitman, 1994): "me é impossível concordar com algumas de suas colocações”, diz ele, "pois presumem que a sociedade está lá, à qual todo mundo de alguma maneira se incorpora, de forma quase automática; e não sei como pode se dar isto” (p. 179). Fox Keller propõe então substituir "observar” por "produzir”, “interatuar”, "participar”. Ao que Glasersfeld sustenta que "tais ações, de cunho obviamente social, são conceitos que precisam antes ser construídos pelo sujeito da experiência e que isto não é sociológico. A sociedade simplesmente não está lá. O social, do ponto de vista do sujeito, é uma experiência subjetiva. Como a sociedade contribui à construção dos indivíduos?”.

Fox Keller segue perguntando: “A família é o mecanismo mediante o qual as sociedades produzem indivíduos. A sociedade define o que constitui o parentesco. E é através desta atividade que as crianças pequenas absorvem, adquirem seus valores, suas identidades sociais. É assim que adquirem parâmetros da sociedade”, diz ela. Glasersfeld responde dizendo que pode concordar com isto, mas que se trata de uma descrição feita de fora. Como saber o que "sabe" o bebê, pergunta ele? Pressupomos que ele "responda afetivamente à mãe”, ou coisa que o valha, mas não estaríamos supondo a reação a um mundo adulto numa criança quando falamos de 
interação? O afeto, “do ponto de vista da criança, é algo que a afeta, mas ela não sabe o que é... ela não sabe no começo que isto é interação com outro ou com outra coisa. Ela se experimenta a si mesmo. A criança tem que aprender a distinguir, ela mesma em sua própria experiência, o que é o outro" (p. 180).

No mesmo volume, no debate que se segue à fala de W. Barnett Pearce, toda fundada numa proposta do construcionismo social - que inclui o discurso das redes, das argumentações, do contexto - acontece uma discussão referente a uma observação de Rorty sobre a importância de argumentações, ainda que más. Glasersfeld (citado por Schnitman, 1994) pondera que "alguém não convence as pessoas com argumentações. Não as convence nem com boas ou más argumentações, as pessoas modificam seu ponto de vista apenas se, por si mesmas, descobrem que algo não funciona” (p. 284, grifo meu). Não por acaso Glasersfeld qualifica seu construtivismo de "radical”.

Buscando na Internet mais informações sobre Glasersfeld, localizei seu site e, através dele cheguei a um site impressionante sobre "Construtivismo Radical” (www.univie.ac.at/ constructivism). Tal qualificativo se justifica pela extraordinária quantidade de informações sobre o construtivismo que o referido site torna disponíveis: 714 URL, além de mais de duzentos artigos completos, relação de pesquisadores e suas instituições de pesquisa, etc. Num pequeno texto somos introduzidos aos proponentes mais eminentes do construtivismo: do setecentista Giambattista Vico, cujo verum ipsum factum já aponta na direção da construção do conhecimento pelo sujeito, ao esse est percepti de George Berkeley, passando pelo biólogo do início do século XX Jacob von Uexkül até os autores contemporâneos como George Kelly, Humberto Maturana, Francisco Varela, Heinz von Foerster e Ernst von Glasersfeld.

O princípio básico do construtivismo radical é que qualquer tipo de conhecimento depende da estrutura do conhecedor. A radicalidade vem na negação de qualquer conhecimento objetivo, estratégia que se revela no tratamento dado à percepção. Ao contrario da fórmula empiricista clássica, que sustenta que a ação é guiada pela percepção, autores construtivistas como Maturana e Varela inverterão a referida fórmula e dirão que na enação (do espanhol en accion) a percepção será guiada pela ação do indivíduo no contexto. Construtivistas como Glasersfeld simplesmente não produzem afirmações sobre o que estaria na "realidade externa".

Para o físico e ciberneticista Heinz Von Foerster (1998) “não vemos que não vemos”, somos cegos em relação à nossa própria cegueira; em outras palavras, só vemos aquilo que nossa experiência elaborou. Particularmente interessante será sua cibernética de segunda ordem, pois esta vai nos permitir um outro olhar, mais implicado sobre o mundo.

A cibernética de primeira ordem separa o sujeito do objeto, ela indica um mundo "lá fora”, totalmente independente. A cibernética de segunda ordem, ou cibernética da cibernética é circular. Aprendemos a nos ver como partes de um mundo a compreender, que queremos observar. Toda situação de descrição penetra num novo campo, no qual precisamos, de repente, assumir a responsabilidade pelas nossas próprias observações. (...) As referências quanto a um mundo independente de nossas observações são substituídas por indicações efetuadas pela própria pessoa. (...) Também a reflexão sobre o sentido e o objetivo das observações que colocamos ganham uma outra dimensão; começamos a tornar claro para nós porque afinal queremos saber ou experenciar. (tradução do autor, p. 16).

Ao invés de correspondência com uma realidade externa (que exige que se obtenha uma verdade absoluta sobre o que se pretende estudar), Glasersfeld considera mais adequado o conceito de viabilidade (fitness). Para pensar esta viabilidade, Glasersfeld (1998) nos dá exemplos de algumas metáforas: de um barco que à noite navega entre recifes, do "vôo cego" de um piloto que opera por instrumentos, de um transeunte numa cidade que ele não conheça bem. Viável será a construção de um "mapa de caminhos possíveis” para o indivíduo, em função de sua experiência. Virginia Kastrup, recentemente, em uma comunicação num congresso, propôs uma bela metáfora que certamente agradaria a Glasersfeld: um sujeito tentando manter aberto seu guarda-chuva numa chuva com muito vento. Não há, em nenhum desses casos uma solução prévia melhor, mais adaptada. O indivíduo terá que elaborar os tais caminhos possíveis através da própria ação refletida.

A propósito da reflexão sobre a ação Glasersfeld (1997) dá um exemplo significativo. Uma menininha está brincando com uma bola que ela vai chutando quando, de repente, surge uma rampa e, para sua surpresa, a bola rola para seus pés. Ao que ela pergunta: "Como a bola chegou até onde eu estou?” (p. 18). Este exemplo permite inferir que a menina está de alguma forma atenta a sua experiência e pode refletir sobre ela. Este é o tipo de questão que, segundo ele, após inúmeras tentativas e assunções leva um pensador imaginativo a formular um princípio de explicação. Glasersfeld quer dar conta desta criação, desta invenção individual.

Num ensaio, no qual presta uma homenagem a Piaget, Glasersfeld (1997) dá a medida exata da sua crítica a abordagens fundadas exclusivamente em determinações sociais ou culturais. É claro que Piaget não ignorou o papel da interação social, pondera ele. Mas Piaget viu também, claramente, que havia uma grande quantidade de conhecimento que o indivíduo poderia adquirir por si próprio. Glasersfeld dá dois exemplos:

Alguns de vocês podem ter testemunhado este fenômeno surpreendente: algumas crianças inventam um método verdadeiramente espetacular de explorar o ambiente enquanto sentadas no penico. Elas certamente não foram instigadas a fazê-lo, nem viram a cena desempenhada por um adulto. É uma realização construída, diríamos, em esplêndido isolamento.

Um feito similar, mas acredito que mais significante culturalmente, foi realizado muito tempo atrás por Pitágoras. Ele poderia estar sentado no terraço em Samos ou Metaponte, olhando ociosamente os padrões dos azulejos do teto. Era o padrão popular de triângulos isósceles congruentes dispostos em quadrados que Sócrates utilizou no Meno de Platão. De repente Pitágoras viu que os quadrados formados no lado longo 
de um triângulo continham quatro dos triângulos, e o quadrado formado no lado mais curto continha dois. Foi a primeira concepção do teorema que o faria famoso por milhares de ano (tradução do autor, p. 22)

Em ambos os casos um conhecimento significativamente novo é construído por uma mente individual, independente, analisa Glasersfeld. E conclui:

Tendo tido já algumas interações com 'construcionistas sociais’ deste país (a palestra está sendo dada nos EUA), imagino que um discípulo zeloso desta escola iria imediatamente contrapor que tais anedotas provariam seus argumentos, pois penicos e azulejos de teto são artefatos sociais. Eu penso que ele erraria o alvo, pois penicos não foram projetados para locomoção e azulejos para a geometria (tradução do autor, p. 22).

Em síntese, as investigações de Glasersfeld visam compreender como o conhecimento é gerado pelos indivíduos. Sua crítica a Vygotsky é significativa. Ao citar um frase do psicólogo soviético (“A aprendizagem humana pressupõe uma natureza especial social através da qual as crianças crescem e se introduzem na vida intelectual daqueles que as cercam”), Glasersfeld (citado por Schnitman, 1994) pondera que, do ponto de vista construtivista, isto equivaleria a declarar, tal como Chomsky o faz, de que a estrutura básica da linguagem é inata, declaração que evita uma investigação sobre como a linguagem poderia ser gerada por aqueles que nasceram numa comunidade lingüística.

Segunda conclusão: o construtivismo tende para o psicologismo.

\section{Comentários e conclusão}

Em recente publicação o psicólogo Luis Botella (2000), da Universidade Ramon Llull de Barcelona, após cuidadosa análise, conclui que o construtivismo compartilha dos mesmos princípios metateóricos que caracterizam o pensamento pós-moderno em Psicologia. Encontramo-nos, portanto, em uma situação bastante curiosa: tanto o construcionismo quanto o construtivismo reivindicam um solo metateórico comum.

Recorrente nas análises pós-modernas da Psicologia, bem no sentido da des-diferenciação acima ressaltada, é a crítica às grandes dicotomias que caracterizaram as teorizações modernas. Visa-se superar tensões como, por exemplo, as que se estabeleceriam entre o interno e o externo, entre o sujeito e o objeto ou - no que tange especificamente ao tema deste artigo, entre o individual e o social. O que salta aos olhos nas análises que venho detalhando é a deliberada manutenção desta última dicotomia, cada modelo estabelecendo, de forma quase metafísica, transcendental, a existência, dir-se-ia $a$ priori, do nível social ou individual. Embora considerandose materialistas, monistas, autores de ambos os modelos permanecem dualistas em sua radicalidade.

Qual seria a réplica de um construcionista social de última geração, como por exemplo Tim Ingold (2000), quanto à última observação de Glasersfeld? "Está certo”, diria ele, “o menino e Pitágoras inventaram conhecimentos novos, mas seu corpo é social, o social está inscrito neles, e é seu corpo” (na expressão difícil de traduzir, o social está embodied neles). Eles vivem em um contexto que os autoriza o brincar, dar pulos e circulam em lugares onde podem ser vistas figuras em formas de triângulos. Nesse sentido não sairiam dando pulos com penicos nem formulariam teoremas geométricos sobre triângulos se antes não houvesse discursos que viabilizassem tais ações. A tréplica de Glasersfeld provavelmente seria semelhante àquela dada a Fox Keller, i.e., de que o social, do ponto de vista do sujeito construtor, seria uma experiência subjetiva e não externa.

Em recente apresentação em um Congresso, expus o exemplo da menina brincando na praça com a bola. A debatedora, professora Angela Branco, da UNB, observou que, antes de mais nada, seria o caso de existirem praças para as crianças poderem brincar; mantendo o espírito de seu exemplo, diria que os "caminhos possíveis" de Glasersfeld esbarrariam em problemas concretos se um dos caminhos possíveis, por um erro na saída da Linha Vermelha, no Rio de Janeiro, levasse o motorista a uma zona proibida por traficantes de drogas e armas, “donos” daquele pedaço da favela. Por outro lado, crianças de favela poderiam improvisar campos de futebol em terrenos baldios e o motorista poderia tentar negociar com os traficantes. Como sair desta discussão circular?

Diria que ambos os modelos simplificam por demais as questões. Se trabalharmos um pouco sobre os últimos exemplos, veremos que as soluções não são pontuais e envolvem ações mais complexas. Assim, se não houver terrenos baldios na favela, haverá a oportunidade de se discutir a necessidade de áreas de lazer para a comunidade numa Associação de Moradores (nível social) através da proposta de um abaixo assinado que uma mãe engajada em resolver o problema encaminhou ao líder da Associação (nível individual) e assim por diante. No que tange ao motorista desastrado, poderia haver uma campanha de educação e informação no trânsito carioca (nível social) e a disposição do motorista em nela se envolver (nível individual). Reath (1997), num artigo em homenagem a John Rawls, sobre a ética pós-kantiana, coloca um argumento magnífico em sua simplicidade: a autonomia individual implica a sujeição a normas sociais. E ele dá o exemplo da linguagem: o fato de nos submetermos a regras gramaticais não nos impede de sermos poetas, o fato de um músico seguir os princípios da harmonia não o impede de ser criativo, ainda que ele modifique estes princípios, como Beethoven ou Piazzola.

A idéia que estou tentando formular tornar-se-á mais clara através do conceito de "híbridos" de Bruno Latour (1994). Latour, um sociólogo e antropólogo das ciências contemporâneo, sustenta que a postura moderna poderia ser caracterizada por uma busca vã de pureza, consubstanciada na obsessão em separar natureza e cultura. Segundo ele estas instâncias não existem em sua pureza. Seu exemplo lapidar é o buraco na camada de ozônio. Ele é natural, afinal os raios que nos afetam são físicos, mas ao mesmo tempo é cultural, pois a poluição é conseqüência de práticas culturais. Estamos, portanto, cercados de híbridos. Os modelos teóricos do construcionismo e o contrutivismo parecem não ter se dado conta de que, na tentativa de reduzir a explicação do compor- 
tamento humano fazendo a balança pesar para o lado do social ou do individual, seus autores incorrem no erro apontado por Latour: vivemos cercados de híbridos de social e individual e não de formas puras destas instâncias.

Nessa linha de raciocínio, o debate entre ciências do espírito e da natureza perde o sentido. Não se trata de afirmar que não existam tais instâncias, mas que elas estão entremeadas e se influenciam mutuamente, não havendo entre elas uma rígida separação por conteúdo. “A divisão demasiado fácil entre ciências naturais (que se ocupam dos fatos) e ciências humanas (que se ocupam dos valores e decisões) deixa de ser possível” (Latour, Schwartz \& Charvolin,1998, p. 102). Para Latour, as ciências humanas incluem as ciências naturais. Não seria o caso de desenvolver este tema aqui, mas esta posição é assumida na filosofia contemporânea por Richard Rorty (1991) numa abordagem pragmática. Nesse sentido a Psicologia seria uma ciência híbrida (híbrida de social e individual, de biológico e cultural). Figueiredo (1993) já observou que a sina da Psicologia seria a de abrigar uma enorme diversidade de matrizes conceituais não sendo viável qualquer tentativa de unificação. No âmbito deste artigo, o que me parece significativo de ressaltar é que o construcionismo e o contrutivismo, ainda que criticando as grandes narrativas, mantêm de forma implícita tal projeto de unificação em torno do social ou do individual , sem assumir a proposta mais complexa e desafiadora de sermos ao mesmo tempo seres individuais e sociais.

Temos que evitar o que o filósofo alemão Karl-Otto Apel chama de contradição performativa: se um psicólogo como Gergen sustenta que tudo é história, ele não deixa de ser um autor, que trabalha e produz no Swathmore College, construindo saberes com seu estilo de pensar e escrever próprios. Rouanet (1993) resume com precisão o conceito proposto por Apel. Suponhamos que alguém afirme que "não existem pretensões de verdade ou veracidade” (p. 223). No momento em que faz esta afirmação, ele está invocando uma pretensão de validade para o que vem afirmar. "O que ele está dizendo no fundo é o seguinte: 'Afirmo, isto é, invoco a pretensão de que minha afirmação é verdadeira e de que estou sendo verídico, e que não tenho nenhuma pretensão de verdade e veracidade’. Surge uma contradição performativa” (p. 223). Penso que o mesmo raciocínio pode ser aplicado aos pensadores construcionistas. No fundo Gergen está dizendo: “Afirmo, como indivíduo, que tudo é história” o que constituiria uma contradição performativa a se manter as posturas reducionistas aqui criticadas.

Chego ao fim deste artigo: o que comprometeria, a meu ver, os dois modelos aqui estudados seriam precisamente suas radicalidades. Como observa Alexandra Tsallis, aluna do Doutorado em Psicologia Social da UERJ, participante do Grupo de Pesquisa sobre a objeto da Psicologia, o construcionismo e o construtivismo teriam que ser menos hard, teriam que assumir uma postura teórica e metodológica mais branda (mais simétrica, diria Latour) que viabilizasse um diálogo entre seus autores. Se nem tudo for social e nem tudo for experiência subjetiva; se minha experiência subjetiva opera com as práticas sociais que o meu contexto propicia, ao mesmo tempo em que posso discordar através da experiência destas práticas inventando novas formas de agir; então o objeto da Psicologia Social se transforma. Não estaremos mais numa Psicologia Social sociológica, nem numa Psicologia cognitiva individual, mas numa Psicologia Social psicológica liberta do "período glacial” do behaviorismo, na feliz expressão de Jean P. Bronckart. Talvez, dissolvendo a dicotomia do social contra o individual, abrindo mão de terminologias que discriminem campos excessivamente delimitados, possamos estabelecer as bases de uma efetiva Psicologia pós-moderna (se aceitarmos as críticas que ambos os modelos estudados dirigem ao modernismo). Ainda uma vez utilizando uma expressão de Bruno Latour (1994), para romper a dicotomia contrutivismo ou construcionismo precisamos assumir uma postura não moderna.

Para finalizar, gostaria de mencionar algumas linhas de pesquisa, das mais fecundas e interessantes, que se abrem a partir desta postura. Citaria dois enfoques, fruto das investigações de meu grupo de pesquisa, que embora diversos daqueles até aqui comentados, não conflitam com as conclusões acima esboçadas. Assim, farei um rápido comentário a propósito do "círculo hermenêutico", de Hans-Georg Gadamer, e do projeto de uma “escultura de si”, de Michel Onfray.

O círculo hermenêutico, que é um "círculo da compreensão”, afirma que podemos compreender o todo somente a partir do individual e o individual apenas a partir do todo. Como isto seria possível? Tal pergunta permaneceria sem resposta se a relação entre o todo e os elementos individuais fosse vista como uma oposição externa. Se reconhecemos a unidade das condições, de lado a lado, torna-se possível que eu conheça o individual através do todo e, ao inverso, o todo através do individual. Nesse sentido, o círculo da compreensão seria então caracterizado como dois momentos coincidentes que não se reduzem um ao outro, que apenas se autorizam permanecer juntos (Tietz, 1999, p. 49). Tal referência teórica abre mais um caminho para solucionar o impasse acima descrito entre indivíduo e sociedade.

Já a proposta de uma “escultura de si” necessitaria de alguns comentários prévios (agradeço estes comentários a meu aluno de pós-graduação Jorge Goia). Frente às "fundamentalizações” reducionistas das correntes a favor do individual ou do social, surgem brechas: uma Psicologia Social psicológica poderia se dar nas alternativas que poderíamos construir enquanto individualidades soberanas, enfrentando um meio social que tende a se impor como rede de formatação da subjetividade. Esta é a proposta de Onfray $(1993,1997)$, cuja filosofia anarquista rejeita uma ordem maior, social, que decida o que deve ser feito, a favor de uma rebeldia ética do indivíduo fundada no hedonismo. Mas estas questões ficam para outros artigos.

\section{Referências}

Botella, L. (2000). Personal construct psychology, constructivismm and postmodern though. Acesso em 05/03/2001 de http://www.massey.ac.nz/ $\sim$ ALock/virtual/Construc.htm.

Chauí, M. (1992). Público, privado, despotismo. In A. Novaes (Org.), Ética (pp. 345-390). São Paulo: Companhia das Letras. 
Figueiredo, L. C. (1993). Matrizes do pensamento psicológico. Petrópolis: Vozes.

Foerster, H. von (1998). Wir sehen nicht, dass wir nicht sehen. Telopolis. Entrevista a Bernard Pörksen. Acesso em 21/03/2001 de www.heise.de/tp/ deutsch/special/robo/6240/1/html.

Gergen, K. (1973). Social psychology as history. Journal of Personality and Social Psychology, 26(2), 309-320.

Gergen, K. (1980). Towards intellectual audacity in social psychology. In R. Gilmour \& S. Duck (Orgs.), The development of social psychology (pp. 239-270). Nova York: Academic Press.

Gergen, K. (1992). Toward postmodern psychology. In S. Kvale (Org.), Psychology and postmodernism (pp. 17-30). Londres: Sage.

Gergen, K. (1994). Exploring the postmodern. American Psychologist, 49(5), 412-416.

Gergen, K. (1996). Theory under threat: Social construction and identity politics. In C. W. Tolman, F. Cherry, R. v. Hezewijk \& I. Lubek (Orgs.), Problems of theoretical psychology (pp. 13-23). North York, Inglaterra: Captus Press.

Gergen, K. (1998). The ordinary, the original, and the believable in psychology's construction of the person. In B. Bayer \& J. Shotter (Orgs.), Reconstructing the psychological subject (pp. 111-125). Londres: Sage.

Glasersfeld, E. von (1998). Welten konstruiren, die für alle gangbar sind. Telepolis. Entrevista com Rudolf Maresch. Acesso em 05/03/2001 de www.heise.de/tp/deutsch/inhalt/co/2572/1.html.

Glasersfeld, E. von (1997). Homage a Jean Piaget. Acesso em 21/03/2001 de www.oikos.org/Piagethom.htm.

Ingold, T. (2000). The Perception of the environment. Essays on livelihood, dwelling and skill. Londres: Routledge.

Lash, S. (1990). Sociology of postmodernism. Nova York: Routledge.

Latour, B. (1994). Jamais fomos modernos. São Paulo: Editora 34.

Latour, B., Schwartz, C., \& Charvolin, F. (1998). Crises nos meios ambientes: desafios às ciências humanas. In H. R. Araújo (Org.), Tecnologia e cultura (pp. 91-125). São Paulo: Estação Liberdade.

Mos, L. (1996). On re-working theory in Psychology. In C. W. Tolman, F. Cherry, R. v. Hezewijk \& I. Lubek (Orgs.), Problems of theoretical psychology (pp. 37-46). Nova York: Captus.
Onfray, M. (1993). La sculpture de soi. Paris: Grasset.

Onfray, M. (1997). Politique du rebelle. Traité de résistance et d'insoumission. Paris: Grasset.

Rappoport, L. (1996). Up, down, and sideways: The possible futures of theory. In C. W. Tolman, F. Cherry, R.v. Hezewijk \& I. Lubek (Orgs.), Problems of theoretical psychology (pp. 33-36). North York, Inglaterra: Captus Press.

Reath, A. (1997). Legislating for a realm of ends: The social dimension of autonomy. In A. Reath, B. Herman \& C. M. Korsgaard (Orgs.), Reclaiming the history of ethics. Essays for John Rawls (pp. 214-239). Cambridge: Cambridge University Press.

Rorty, R. (1991). Objectivity, relativism and truth. Philosophical papers, volume 1. Cambridge: Cambridge University.

Rouanet, S. P. (1993). Mal-estar na modernidade. São Paulo: Companhia das Letras.

Schmidt, N. (1995). Philosophie und Psychologie. Hamburgo: Rowohlt Enzyklopädie.

Schnitman, D. F. (1994). Nuevos paradigmas, cultura y subjetividad. Buenos Aires: Paidós.

Shotter, J. (1992). 'Getting in touch': The meta-methodology of a postmodern science of mental life. In S. Kvale (Org.), Psychology and postmodernism (pp. 58-73). Londres: Sage.

Shotter, J. (1996). Wittgenstein in practice: From the way of theory to a social poetics. In C. W. Tolman, F. Cherry, R. v. Hezewijk \& I. Lubek (Orgs.), Problems of theoretical psychology (pp. 3-12). North York, Inglaterra: Captus Press.

Shotter, J. (1997). Cognition as a social practice. In D. M. Johnson \& C. E. Erneling (Orgs.), The future of cognitive revolution (pp. 317-334). Oxford: Oxford University Press.

Shotter, J. (1998). Social construction as social poetics: Oliver Sacks and the case of Dr. P. In B. M. Bayer \& J. Shotter (Orgs.), Reconstructing the psychological subject (pp. 33-51). Londres: Sage.

Tietz, U. (1999). Hans-Georg Gadamer. Hamburgo: Junius Verlag Gmbh.

Tolman, C. W., Cherry, F., Hezewijk \& Lubek, I. (Orgs.). (1996). Problems of theoretical psychology. North York, Inglaterra: Captus Press.

\section{Nota}

1 Colaboração de Jorge Goia, doutorando em Psicologia Social da UERJ, bolsista da FAPERJ. E-mail:

jorge.goia@matrix.com.br.

Ronald João Jacques Arendt, doutor em Psicologia pela Fundação Getúlio Vargas (RJ), é professor titular do Instituto de Psicologia da Universidade do Estado do Rio de Janeiro - UERJ (RJ). Endereço para correspondência: Rua Marechal Marques Porto, 2, ap. 903, Tijuca, 20270-260, Rio de Janeiro, RJ. Tel. (21)2567.2352. Fax (21)2587.7284. E-mail: rarendt@unisys.com.br. 